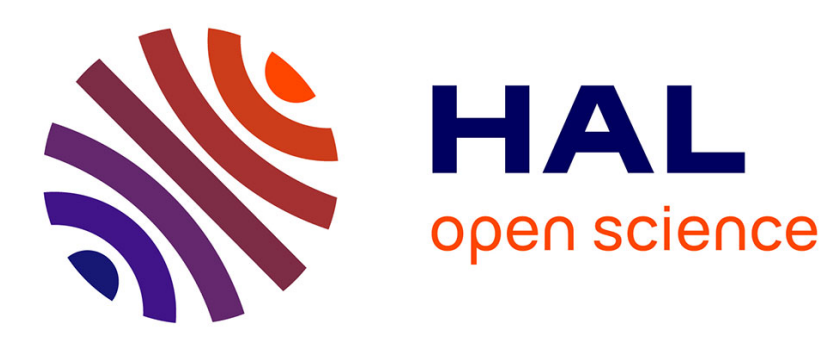

\title{
A study of the impact of humid aging on the strength of industrial adhesive joints
}

Romain Léger, A. Roy, J.-C. Grandidier

\section{To cite this version:}

Romain Léger, A. Roy, J.-C. Grandidier. A study of the impact of humid aging on the strength of industrial adhesive joints. International Journal of Adhesion and Adhesives, 2013, 44, pp.66 - 77. 10.1016/j.ijadhadh.2013.02.001 . hal-01883671

\section{HAL Id: hal-01883671 \\ https://hal.science/hal-01883671}

Submitted on 3 Nov 2020

HAL is a multi-disciplinary open access archive for the deposit and dissemination of scientific research documents, whether they are published or not. The documents may come from teaching and research institutions in France or abroad, or from public or private research centers.
L'archive ouverte pluridisciplinaire HAL, est destinée au dépôt et à la diffusion de documents scientifiques de niveau recherche, publiés ou non, émanant des établissements d'enseignement et de recherche français ou étrangers, des laboratoires publics ou privés. 


\title{
A study of the impact of humid aging on the strength of industrial adhesive joints
}

\author{
R. Leger ${ }^{a, *}$, A. Roy ${ }^{b}$, J.C. Grandidier ${ }^{c}$ \\ ${ }^{a}$ Centre des Matériaux des Mines d'Alès C2MA, Ecole des Mines d'Alès, 6 Avenue de Clavières, F-30319 Alès Cedex, France

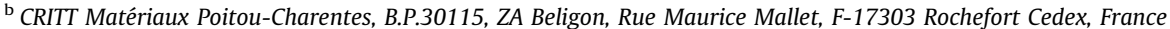 \\ ' Département de Mécanique et Physique des Matériaux, Institut P', CNRS, Université de Poitiers, ENSMA, UPR 3346, Téléport 2, 1 Avenue Clément Ader, B.P.40109, F-86961 \\ Futuroscope Chasseneuil Cedex, France
}

\section{A B S T R A C T}

This paper aims at investigating the aging of a single lap joint (SLJ) in water at $70{ }^{\circ} \mathrm{C}$. Experimental observations show an important decrease of deformability from 1 day of aging, while initial behaviour is not impacted. Further investigations reveal that the initial crack occurs at the interface near extremities of overlaps at a load depending from aging time. To predict the behaviour of the aged SLJ submitted to tensile loading, it is necessary to know precisely the state of stress in the adhesive layer and at the interface. The authors develop a finite element model to simulate the diffusion of water in the adhesive layer of the SLJ and the subsequent residual strength testing. The mechanical behaviour of the adhesive is predicted by a coupled elasto-plastic law which is deduced from an experimental work on bulk adhesive aged in water. It can model simultaneously its intrinsic behaviour as a function of temperature and water concentration and allow predicting the tensile tests on aged adhesive specimens and the volume change due to temperature and diffusion of water. Using the finite element software ABAQUS, the authors show that during diffusion of water, stresses can be important in the adhesive layer and can generate small damage. Then, for a load that led without aging to crack initiation and final fracture, stress field in the aged adhesive layer is not that critical. Such results tend to confirm that interface has been mostly impacted and weakened by water.

Keywords:

Epoxy/epoxides

Interface

Finite element stress analysis

Aging

Coupled multiphysics

\section{Introduction}

It is now widely recognised by industrials that adhesive structural bonding can replace other joining method, since a well dimensioned bonded joint can provide an equivalent strength compared with bolted specimen for example. Moreover, structural bonding provides the ability to be more resistant in crashes and to obtain low weight structures and to greatly simplify the assembly process. But, this technique is still carefully employed by industrials for highly loaded structures as, for example, in the aeronautics, or for structures working in aggressive humid environment as for offshore and marine structures. To guarantee the durability of such structures, bolting [1] and overlamination [2,3] are sometimes being used in addition with bonding and conservative design is realized which cancel the advantages of bonding.

\footnotetext{
* Correspondence to: Centre de Recherche C2MA, Ecole des Mines d'Alès, 6 Avenue de Clavières, F-30319 Ales Cedex, France. Tel.: +3346678 5688; fax: +33466785680.

E-mail address: romain.leger@mines-ales.fr (R. Leger).
}

A lot of work has been done in the past decades to evaluate the impact of humid aging on the strength of bonded structures. The aim is to predict the durability (i.e. an optimal period of use or a maximal load level) of adhesive joints submitted to various mechanical loads combined with environmental degradation. Such studies are very complex since a lot of phenomenon takes place in the joint at the same time and are often coupled. Actually, it is known that a humid environment is responsible for a plasticisation of the adhesive which results in a decrease in $T_{\mathrm{g}}$ [4-6] and mechanical properties [7,8]. As water ingresses in the adhesive (transient process), a differential swelling takes place which results in gradients of stress [9]. Moisture is also responsible in some cases of permanent degradation such as hydrolysis [10-12] or osmotic degradation which results in cavitation $[13,14]$. To evaluate the impact of humid aging, various mechanical tests such as tensile tests $[7,15]$, torsion test $[16,17]$ or pure shear test with Arcan specimens [18,19], are carried out on degraded adhesive joints where a decrease of strength and a change of fracture mode is generally observed. Some authors also investigated the evolution of adhesive fracture energy after aging with specific fracture-mechanics tests such as the wedge test $[8,20]$ and the DCB and TDCB test $[21,22]$. 
Those tests give access to a lot of essential data on the behaviour of adhesives and joints after aging. To predict the lifetime of a bonded structure submitted to humid environment, it is necessary to evaluate the state of stress in the adhesive, interface and adherent at any time of aging, and compare this value to the failure stress or a failure criteria which depends on water content. One can also predict the crack propagation if needed. Such prediction is not easy to obtain since the diffusion is a transient process and gradients of mechanical properties appear. Analytical studies provide complicated systems of equation which can only be solved by computers. Finite element method is preferred by many authors, to study the aging of adhesive joints [18,23-26]. The classical process to predict the residual strength or service life of a bonded structure is well described by Crocombe in [27]. It is first, necessary to study the diffusion process of moisture in the adhesive layer that is to say in the bulk adhesive and at the interface. Mass and volume of coupons are followed during humid aging and the diffusion kinetic is deduced from this result. Then, the evolution (decrease) of mechanical properties as a function of water content is measured on little specimens of bulk adhesive. When the study concerns the propagation of a crack, a separation law is also determined [24,25]. Thanks to a relevant FE model, it is possible to simulate the diffusion of water in an important structure and obtain the concentration of water and the subsequent gradients of mechanical properties and stress (due to swelling) in every point. By applying a load on the FE model, one can obtain the state of stress or the crack propagation which depends on the humid aging.

In the automotive field, a normalised test (tension-shear) is carried out on a single lap joint aged in water at $70{ }^{\circ} \mathrm{C}$ during 14 days. It is very difficult to know precisely the stress field in the joint during such test. Effects of temperature and humidity combine during aging and final fracture is the consequence of physical aging, loading induced by aging and subsequent mechanical loading. According to the author, work on such test with severe aging (aging temperature close to glass transition temperature) has not been published yet. As a consequence, it is difficult without a numerical analysis of this test, to associate the fracture of the aged adhesive joint to the interface aging or to the adhesive aging, to the decrease of mechanical properties of adhesive or to the loss of adhesion (destruction of chemical bonds between adhesive and substrates). The aim of this paper is to fulfil this part of the knowledge by creating a numerical model that can include thermohydromechanical coupling effects on the behaviour of the adhesive. Thanks to this tool, stress fields during aging and fracture test will be established and the physical source of phenomenon leading to fracture will be discussed. To achieve this, the author's work is based on a non-linear diffusion law described in [14] which have been integrated in a finite element model. Simulation of water diffusion at various temperatures gave satisfactory results. In the present paper, the impact of 14 days of aging in water at $70{ }^{\circ} \mathrm{C}$ on the behaviour of single lap joint and fracture modes is investigated. Then, a coupled thermohydromechanical behaviour law is elaborated on the ground of tests on bulk adhesive in order to predict an estimation of the state of stress in the bulk adhesive during the aging period and mechanical test. This law is then included in a finite element model of a bonded specimen. Simulation of tensile tests on the joint are carried out and compared with experiments. Stress field in the adhesive layer is analysed to identify the mechanisms responsible for the fracture of the adhesive joint.

\section{Experimental observations}

The adhesive under investigation is a commercial one-part rubber toughened epoxy (DGEBA)/ amine (DDA) used as a "crash" adhesive in the automotive field. It also contains mineral fillers (mainly Si-/Ca-based, $\approx 25 \mathrm{wt} \%$ ), rubber nodules and other additives (accelerators, plasticizers,...). It has been studied by the authors in [14] and by Calvez et al. in [28]. It has been used to produce single lap joints (Fig. 1) with galvanised steel substrates ( $0.7 \mathrm{~mm}$ thickness) which have been skin-passed, and greased $\left(2.5 \mathrm{~g} / \mathrm{m}^{2}\right)$. This skin-pass step (also called cold rolling step) has been previously reported $[28,29]$, and consists in creating a specific plateau/valley topography $\left(R_{a}=1 \mu \mathrm{m}\right.$ and $\left.R_{z}=5 \mu \mathrm{m}\right)$ improving mechanical adhesion between adhesive and substrates and the subsequent mechanical properties of the joint. Bonded joints are cured in an oven at $180{ }^{\circ} \mathrm{C}$ during $40 \mathrm{~min}$ and are then cooled at ambient temperature. Sheets of bulk adhesive $(2.5 \mathrm{~mm}$ thickness) were also prepared and dog-bone specimens were machined (section $2.5 \times 2.5 \mathrm{~mm}^{2}$ ). Details on manufacturing are given in [14]. All specimens are dried after their manufacture and stored under vacuum at ambient temperature.
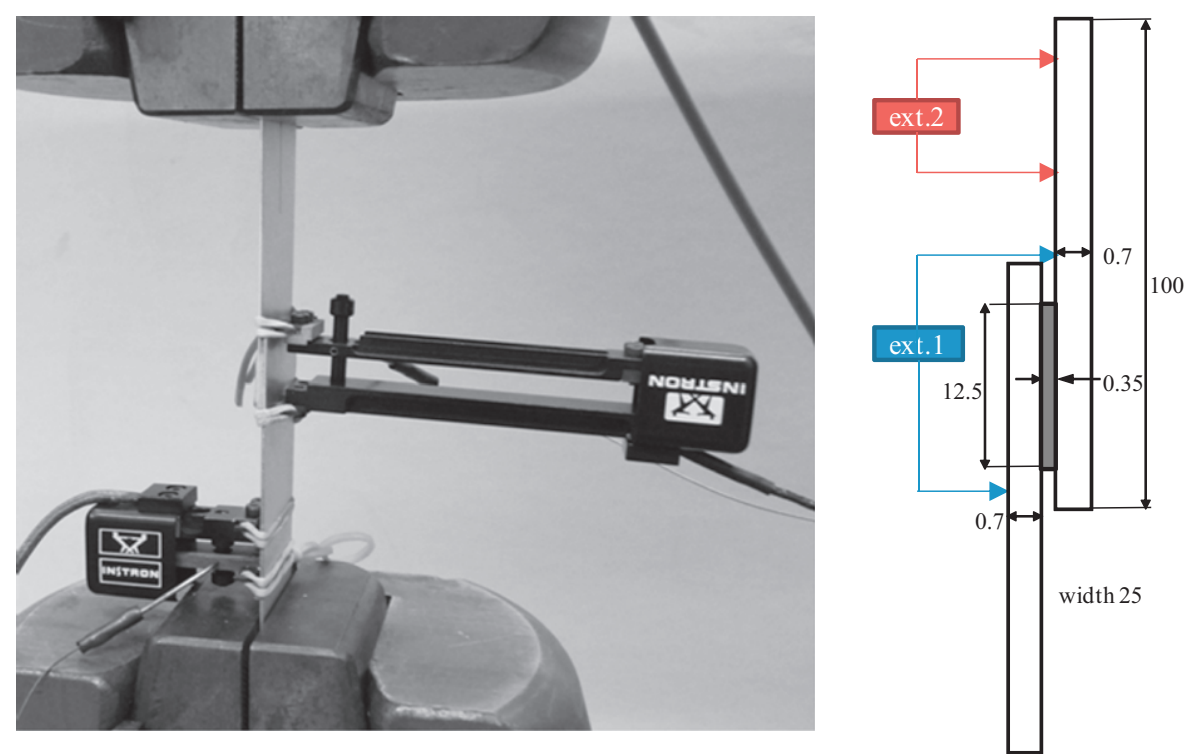

Fig. 1. Tensile tests set-up for adhesive joints (dimensions are in $\mathrm{mm}$ ). 


\subsection{Impact of aging in water at $70{ }^{\circ} \mathrm{C}$ on the bonded joint}

Adhesive joints are immersed in demineralised water at $70{ }^{\circ} \mathrm{C}$ during 1, 5 and 14 days. After aging, specimens are exposed during 10 min to ambient temperature. Three joints are submitted to
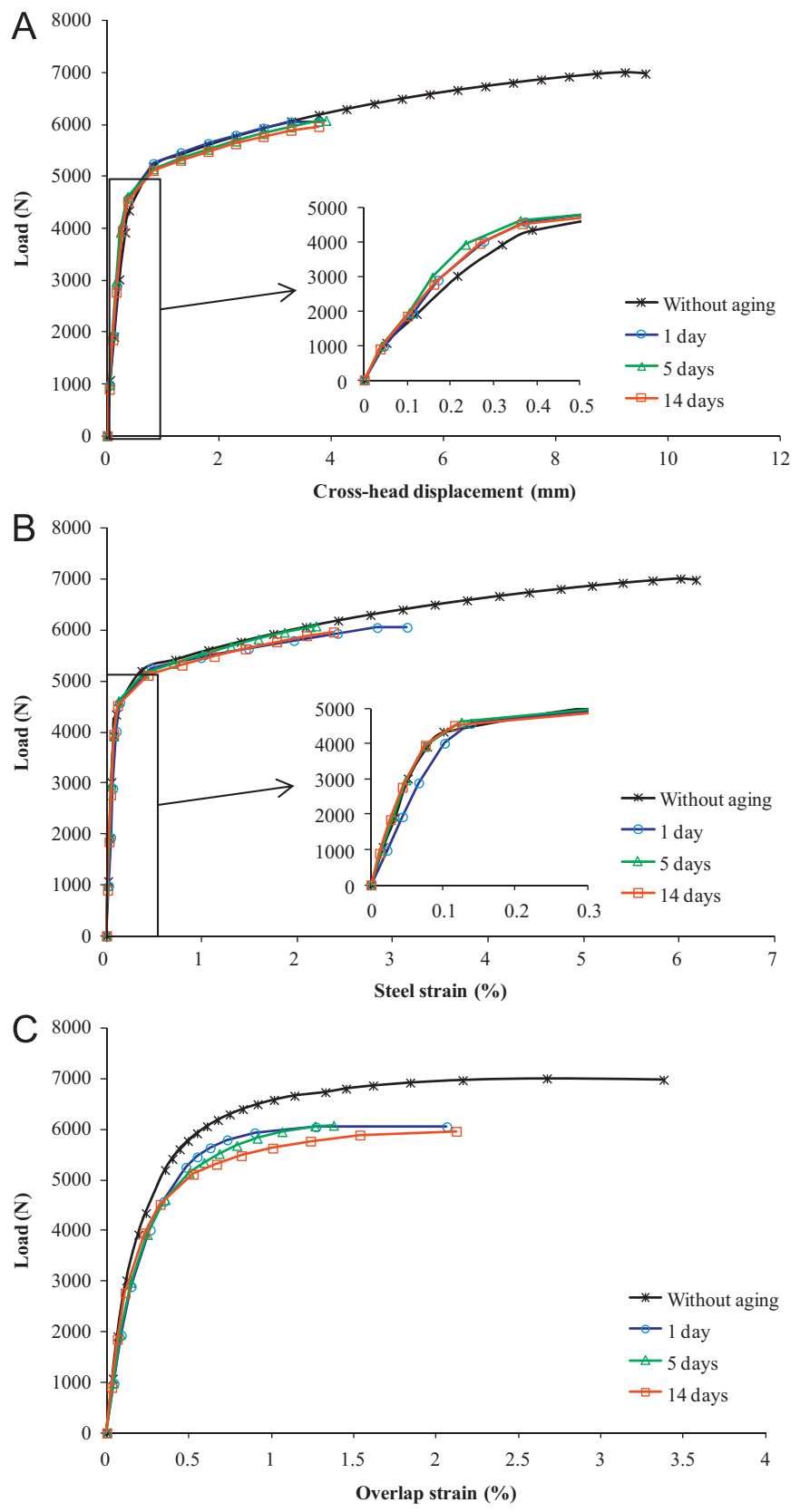

Fig. 2. Impact of humid aging at $70{ }^{\circ} \mathrm{C}(1,5$ and 14 days $)$ on the behaviour of: A - the bonded joint, B-the galvanised steel measured with extensometer 2, C-the overlap measured with extensometer 1 . tensile loading at a crosshead speed of $10 \mathrm{~mm} / \mathrm{min}$ on an Instron 4505 fitted with a $100 \mathrm{kN}$ load cell. As shown in Fig. 1 extensometer 2 give access to the strain of one substrate during the deformation of the whole bonded joint while extensometer 1 measures the deformation of the overlap, i.e. the adhesive layer that shear and part of the two substrates in tension. Fig. 2 displays the behaviour of the entire SLJ (load as a function of crosshead displacement), the behaviour of the galvanised steel (load as a function of strain measured with extensometer 2) and the behaviour of the overlap (load as a function of strain measured with extensometer 1) which depends in part of the behaviour of the adhesive when submitted to tensile loading. Only one curve is represented on the figure, but each time three samples have been tested giving a good reproducibility. Before aging, failure load is close to $7000 \mathrm{~N}$. The initial behaviour of the entire lap joint is linear and corresponds to the elastic behaviour of the substrate. The second non-linear step starting from $5000 \mathrm{~N}$ corresponds to the plastic deformation of the galvanised steel (comparison between $\mathrm{A}$ and B in Fig. 2). This step also appears in Fig. 2-C and corresponds to the plasticisation of steel near overlap. Three other tests were carried out and stopped at 6000, 6500 and $6900 \mathrm{~N}$. The overlap was carefully investigated to observe the initiation of crack at the interface substrate/adhesive (Fig. 3). At $6000 \mathrm{~N}$, a whitening of the adhesive appears, revealing an important cavitation and the
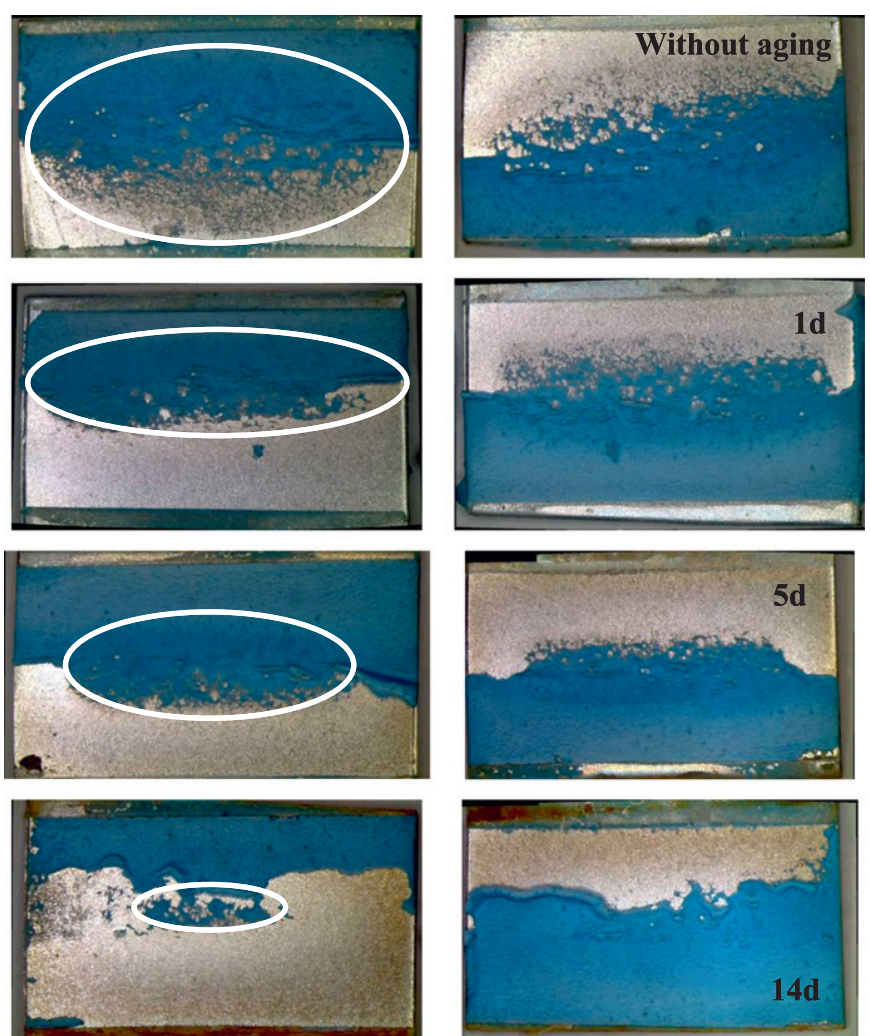

Fig. 4. Fracture surface of unaged and aged SLJ specimens (1, 5 and 14 days).
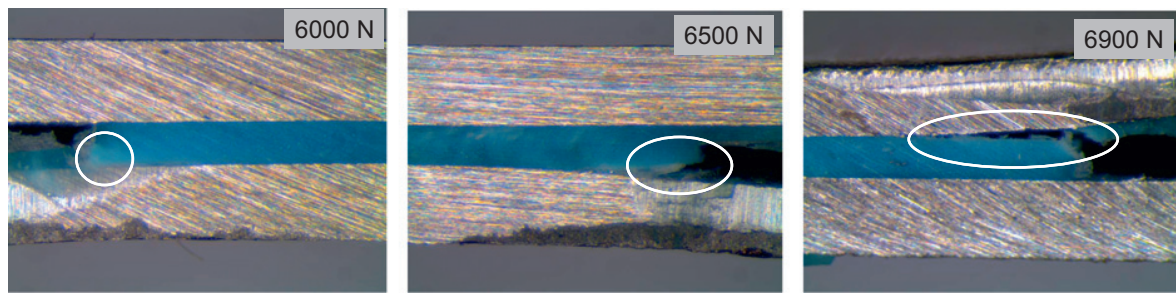

Fig. 3. Observation of overlap before aging at 6000,6500 and $6900 \mathrm{~N}-$ Crack initiation. 
crack initiation. For higher loads, crack appears and seems to propagate along the interface. Fracture surface are investigated in Fig. 4. Cohesive (white circle) and adhesive fracture zones are visually estimated. Before aging, the final fracture occurs partly at the interface $(\approx 20 \%)$ and in the adhesive layer $(\approx 80 \%)$.

Aging did not impact the initial stiffness of bonded joints (Fig. 2) since steel substrates are mainly responsible for the global behaviour. Aging only impacts the displacement and load at fracture. But it seems that time of immersion does not impact those values. Of course, substrates are less deformed and are not mechanically impacted by aging period (Fig. 2). Plasticisation of the adhesive layer is more easily observable on Fig. 2-C where the load at the beginning of non-linearity decreases as the aging time increases. Fig. 4 clearly displays the increase of interfacial fracture. After 14 days of aging the fracture almost entirely occurs at the interface (debonding).

At first, these observations seem to reveal that interface is strongly impacted by water and is mainly responsible for the decrease of mechanical properties of the assembly and the change of fracture mechanism. But the problem is very complicated and such conclusion is made too early. On one hand, diffusion of water generates differential swelling in the adhesive layer and since it is confined between two steel substrates, overstress appears during aging. At the same time, mechanical properties of the adhesive decrease because of water and so the stress field changes. Without numerical tool taking into account these coupling effects, it is not possible to evaluate the state of stress in the joint neither

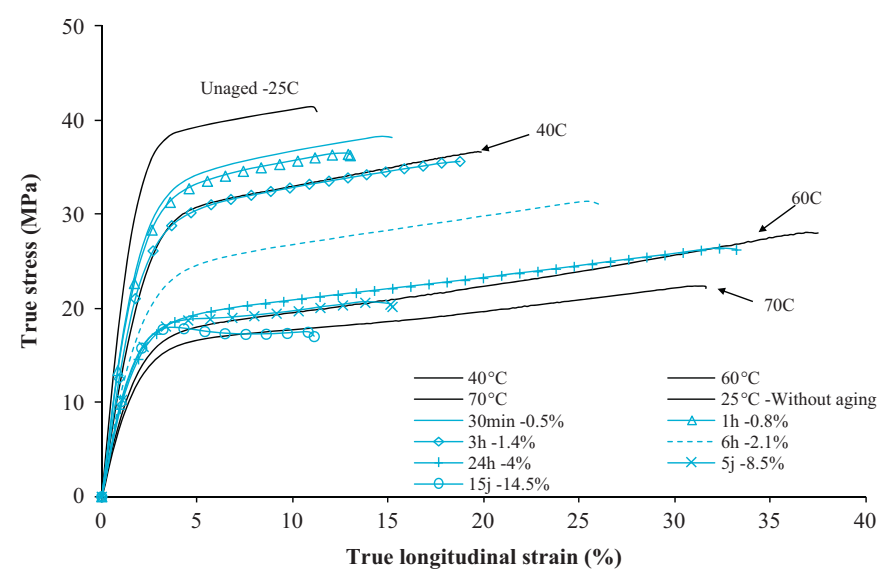

Fig. 5. Experimental impact of water and temperature on the tensile properties of bulk adhesive. For aged specimens, the first value in the legend corresponds to the aging time, the second to the water content in mass before loading. analyse Fig. 4. On the other hand, the interface is likely to be impacted during aging. Some authors show that water can diffuse faster along the interface than in the adhesive layer [30,31], but such tendency is not always confirmed. It is very complicated to conclude on the behaviour of the interface during this test and it is difficult to evaluate diffusion at the interface. However, if a numerical tool is developed predicting the mechanical behaviour of the aged adhesive, stresses at interface before fracture will be determined by simulating the tensile test on bonded assembly. Indirectly, the decrease of intrinsic interface's properties could be roughly evaluated.

\subsection{Impact of aging in water at $70{ }^{\circ} \mathrm{C}$ on the bulk adhesive}

Tensile tests have been carried out on bulk adhesive dog-bone specimens on an Instron 1195 fitted with a $500 \mathrm{~N}$ load cell. A digital camera and specific software are employed to obtain longitudinal and transversal deformation. The impact of temperature and water on classic tensile data (Young's modulus, Poisson's ratio, and ultimate stress and strain) are evaluated. Dry specimens are placed between clamps and load is maintained at $0 \mathrm{~N}$ during 20 min to obtain homogeneous temperature $\left(25,40,60\right.$ and $\left.70{ }^{\circ} \mathrm{C}\right)$ in the section before tensile test. Other specimens are immersed in water at $70{ }^{\circ} \mathrm{C}$ during $30 \mathrm{~min}, 1,3$ and $6 \mathrm{~h}, 1,5$ and 15 days. Before tensile test, those coupons are wiped dry and cooled down at $25^{\circ} \mathrm{C}$ (the small amount of water desorbed during this step is neglected). For each condition, three specimens are loaded in tension. Average curves are plotted in Fig. 5 and main results are summarised in Table 1.

Mechanical properties decrease when temperature rises and gets closer to the glass transition temperature $\left(\approx 95{ }^{\circ} \mathrm{C}\right)$. The moderate decrease of ultimate strain between 60 and $70{ }^{\circ} \mathrm{C}$ is probably due to a thermolysis. As water ingresses in the bulk adhesive, it plasticises the matrix causing a decrease of Young's modulus and fracture stress, while fracture strain increases. After 1 day of aging, ultimate strain decreases because of the increasing presence of cavities as mentioned in a previous paper of the authors [14].

\section{Determination of the adhesive behaviour law as a function of humid aging}

The aim of this part is to determine the intrinsic impact of water and temperature on the bulk adhesive and develop a coupled behaviour law that can be implemented in a finite element model to predict the stress field during aging and loading of bonded joints. This law will allow determining stresses and

Table 1

Experimental impact of temperature on unaged adhesive (upper table) and impact of a $70{ }^{\circ} \mathrm{C}$ water aging time (lower table) on Young's modulus, ultimate stress and strain.

\begin{tabular}{|c|c|c|c|c|c|c|c|c|}
\hline \multicolumn{2}{|c|}{ Impact of temperature } & \multicolumn{2}{|l|}{$25^{\circ} \mathrm{C}$} & \multicolumn{2}{|l|}{$40^{\circ} \mathrm{C}$} & \multicolumn{2}{|l|}{$60{ }^{\circ} \mathrm{C}$} & $70^{\circ} \mathrm{C}$ \\
\hline \multicolumn{2}{|l|}{$\mathrm{E}(\mathrm{MPa})$} & \multicolumn{2}{|c|}{$2200 \pm 100$} & \multicolumn{2}{|l|}{$1400 \pm 80$} & \multicolumn{2}{|l|}{$850 \pm 40$} & $800 \pm 40$ \\
\hline \multicolumn{2}{|l|}{ v } & \multicolumn{2}{|c|}{$0.47 \pm 0.03$} & \multicolumn{2}{|l|}{$0.42 \pm 0.01$} & \multicolumn{2}{|l|}{$0.41 \pm 0.02$} & $0.40 \pm 0.01$ \\
\hline \multicolumn{2}{|l|}{$\sigma_{\text {ultimate }}(\mathrm{MPa})$} & \multicolumn{2}{|c|}{$41 \pm 1$} & \multicolumn{2}{|l|}{$36 \pm 1.5$} & \multicolumn{2}{|l|}{$28 \pm 1$} & $22 \pm 0.7$ \\
\hline \multicolumn{2}{|l|}{$\varepsilon_{\text {ultimate }}(\%)$} & \multicolumn{2}{|l|}{$12 \pm 1$} & \multicolumn{2}{|l|}{$19 \pm 2$} & \multicolumn{2}{|l|}{$35 \pm 5$} & $27 \pm 5$ \\
\hline \multicolumn{2}{|l|}{$\left|T-T_{\mathrm{g}}\right|\left({ }^{\circ} \mathrm{C}\right)$} & \multicolumn{2}{|l|}{70} & \multicolumn{2}{|l|}{55} & \multicolumn{2}{|l|}{35} & 25 \\
\hline Impact of aging & No aging & $30 \mathrm{~min}$ & $1 \mathrm{~h}$ & $3 \mathrm{~h}$ & $6 \mathrm{~h}$ & $24 \mathrm{~h}$ & $5 \mathrm{~d}$ & $15 \mathrm{~d}$ \\
\hline$E(\mathrm{MPa})$ & $2200 \pm 100$ & $1860 \pm 50$ & $1570 \pm 100$ & $1550 \pm 120$ & $1170 \pm 60$ & $1080 \pm 70$ & $1080 \pm 60$ & $1050 \pm 50$ \\
\hline v & $0.47 \pm 0.03$ & $0.47 \pm 0.01$ & $0.46 \pm 0.02$ & $0.46 \pm 0.01$ & $0.45 \pm 0.03$ & $0.45 \pm 0.01$ & $0.44 \pm 0.02$ & $0.44 \pm 0.02$ \\
\hline$\sigma_{\text {ultimate }}(\mathrm{MPa})$ & $41 \pm 1$ & $38 \pm 0.7$ & $34 \pm 0.3$ & $35 \pm 0.3$ & $31 \pm 0.5$ & $26 \pm 0.5$ & $20 \pm 1$ & $17 \pm 0.5$ \\
\hline$\varepsilon_{\text {ultimate }}(\%)$ & $12 \pm 1$ & $15 \pm 2$ & $14 \pm 2$ & $17.5 \pm 3$ & $27 \pm 1$ & $33 \pm 1.5$ & $19 \pm 0.5$ & $12 \pm 3$ \\
\hline$\left|T-T_{\mathrm{g}}\right|\left({ }^{\circ} \mathrm{C}\right)$ & $70^{-}$ & 61 & 58 & 51 & $46^{-}$ & 38 & 33 & $33^{-}$ \\
\hline
\end{tabular}


gradients of properties as a function of local adhesive temperature and water concentration. The main difficulty with the adhesive of the study is that, at high temperature, a lot of water is absorbed and consequently there are important gradients of water concentration and mechanical properties. Another difficulty consists in extracting a thermohydromechanical intrinsic behaviour from such tests where measures are averaged as a function of gradients in the section.

To establish such law, it is necessary to analyse in detail the experiments. It is fundamental to know the water concentration field in the specimen, for example, by running a simulation like it is proposed by the authors in [14]. The heterogeneity of water concentration in the cross-section of specimen is taken in account for analysing the tensile test.

\subsection{Influence of water and temperature on the mechanical properties of the adhesive}

The objective is to develop a behaviour law that can give the adhesive mechanical properties for any temperature and water concentration. The difficulty is to distinguish coupled effects generated by water from temperature effects. More precisely, water plasticizes bulk adhesive and its mechanical behaviour decreases. But, as it can be seen in Fig. 5, the same decrease occurs when temperature increases and gets closer to the $T_{\mathrm{g}}$. At this point, it is not possible to distinguish the intrinsic impact of water on mechanical properties from the decrease of $T_{g}$ generated by water. To answer that point, one can rely on tests at different temperatures on dry specimens and tests at $25{ }^{\circ} \mathrm{C}$ on aged specimens. Results are then analysed and compared considering the parameter $\left|T-T_{\mathrm{g}}\right|$, the distance between aging temperature and local glass transition temperature. As water plasticizes the adhesive matrix, $T_{\mathrm{g}}$ directly depends on water concentration. For each testing conditions of Fig. 5, a value of $\left|T-T_{\mathrm{g}}\right|$ can be attributed (Table 1). For tensile tests at various temperatures, ambient temperature changes, but $T_{\mathrm{g}}$ is the same for each coupons. $\mid T-$ $T_{\mathrm{g}} \mid$ decreases when $T$ increases ( $T_{\mathrm{g}}>T$ in those cases). For tensile tests of aged coupons, $T_{\mathrm{g}}$ decreases when water diffuses while ambient temperature remains the same $\left(25^{\circ} \mathrm{C}\right)$. The total amount of water in each specimen is known and since the evolution of $T_{\mathrm{g}}$ as a function of water concentration has been determined in [14] (Fig. 6), an average value of $T_{\mathrm{g}}$ can be deduced for each tests. In Figs. 7-9, mechanical parameters deduced from those two types of tests are plotted as a function of $\left|T-T_{\mathrm{g}}\right|$. The evolution of yield and ultimate stresses and strains (and consequently the hardening behaviour) is proportional to $\left|T-T_{g}\right|$ for both temperature and aging tests. Points are on the same curve. As a consequence, there is no intrinsic impact of water on those parameters. In other words, the drift of $T_{\mathrm{g}}$ is mainly responsible for the evolution of those parameters. About Young's modulus (Fig. 7), for both types

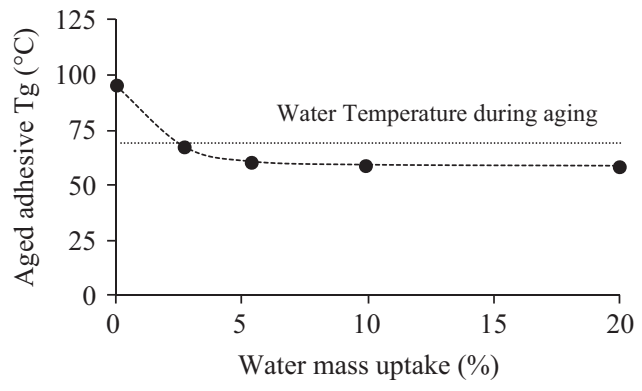

Fig. 6. Experimental $T_{\mathrm{g}}$ change with water content (horizontal line indicates the temperature of water during the aging test).

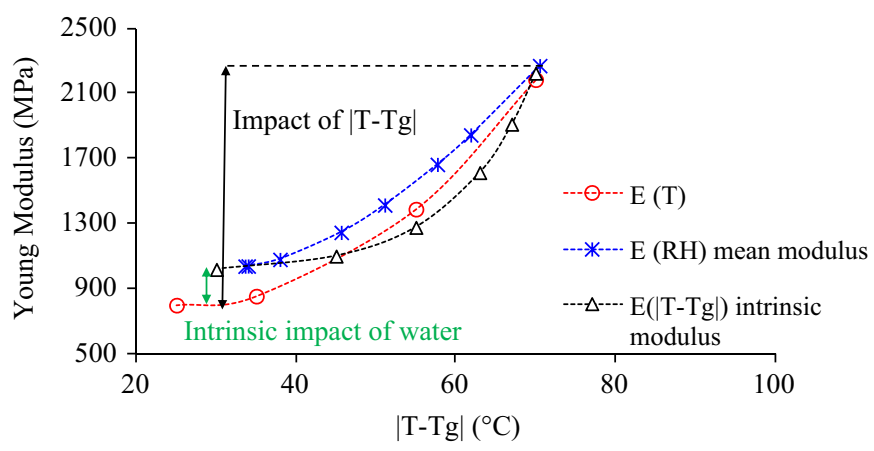

Fig. 7. Experimental evolution of Young's modulus as a function of $\left|T-T_{\mathrm{g}}\right|$ for tensile tests in temperature and after aging in water. $E(T)$ : value obtained during tensile test in temperature, $E(\mathrm{RH})$ : mean modulus value obtained during tensile test on aged coupons, $E\left(\left|T-T_{\mathrm{g}}\right|\right)$ : simulated evolution of $E$ which takes into account the coupled effect of water and temperature (proposed behaviour law).

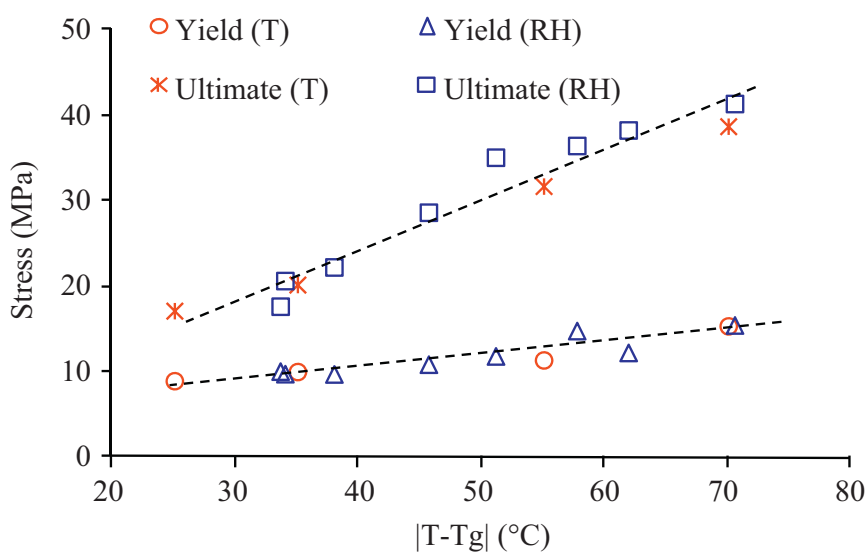

Fig. 8. Experimental evolution of ultimate and yield stresses as a function of $\mid T-T_{\mathrm{g}}$ for tensile tests in temperature and after aging in water. Ultimate $(T)$ : value obtained during tensile test in temperature, Ultimate $(\mathrm{RH})$ : mean value obtained during tensile test on aged coupons.

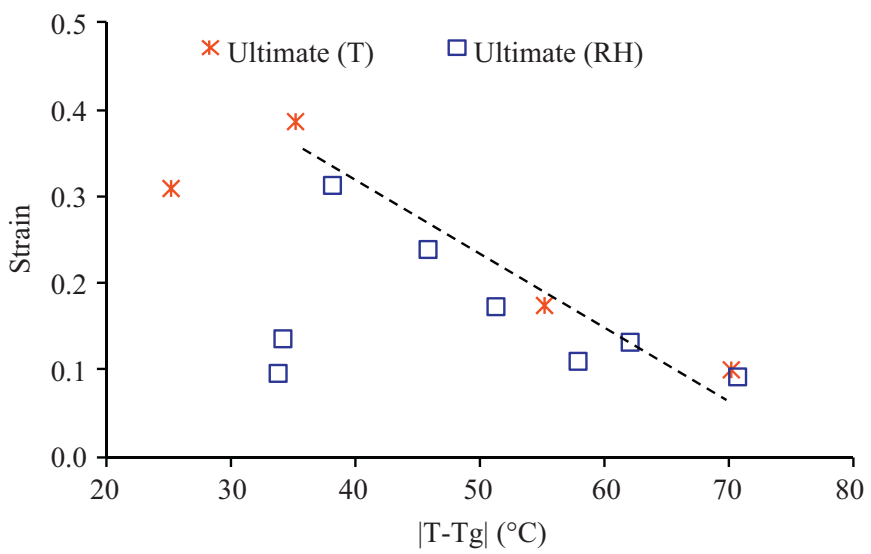

Fig. 9. Experimental evolution of ultimate strain as a function of $\left|T-T_{\mathrm{g}}\right|$ for tensile tests in temperature and after aging in water. Ultimate $(T)$ : value obtained during tensile test in temperature, Ultimate $(\mathrm{RH})$ : mean value obtained during tensile test on aged coupons.

of test, when $\left|T-T_{\mathrm{g}}\right|$ decreases, the same tendency is observed for $E$. However its evolution depends on the test. It is important to remember that in the aging test, there are water concentration gradients and only an average value of $E$ is obtained. Young's modulus is low at edges and unchanged in the middle of the specimen. 
The method to distinguish coupled effects is to simulate by finite elements the diffusion of water in those specimens to obtain the water concentration gradients and subsequent $T_{\mathrm{g}}$ and $\left|T-T_{\mathrm{g}}\right|$ in their section. So an intrinsic law, linking $E$ and $\left|T-T_{\mathrm{g}}\right|$ and the integrating coupled effect of water and temperature on $E$ can be evaluated by confronting simulations on samples with water concentration gradients with experimental results.

We use the diffusion model described in [14]. This model gave good predictions of the mass uptake of specimens immersed in water at $25,40,60$ and $70{ }^{\circ} \mathrm{C}$.

With this numerical tool, diffusion of water at $70^{\circ} \mathrm{C}$ in a section-squared specimen is simulated. Results are displayed in Fig. 10 for 30 min, 6 h, 1 and 5 days of immersion. This simulation gives access for example to the value of $T_{\mathrm{g}}$ in every point of the section. One can see that after only $30 \mathrm{~min}$ of immersion in water, $75 \%$ of the cross section $\left(2 \times 2 \mathrm{~mm}^{2}\right)$ of the sample is already affected. This means that $75 \%$ of the local material's mechanical properties have already decreased.

The law $E=f(T)$ in Fig. 7 (red curve) is first employed to evaluate the experimental "mean" Young's modulus of the specimen aged in water. It can be seen that such law does not give satisfactory results (large dots in Fig. 11). The value of $E$ is overestimated for short time immersion while it is underestimated for long time immersion. A correction of this law, integrating the intrinsic impact of water, is proposed (blackcurve in Fig. 7)

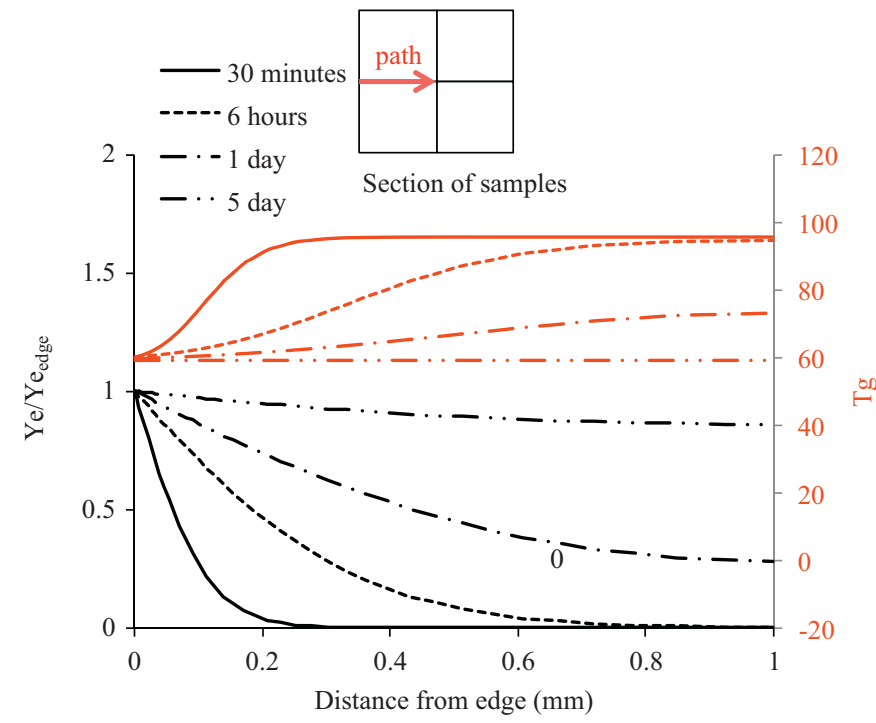

Fig. 10. Ratio of simulated local water concentration $\left(Y_{\mathrm{e}}\right)$ by the water concentration at saturation ( $Y_{\mathrm{e}}^{\text {edge }}$ ) and local $T_{\mathrm{g}}$ along a path represented above, for bulk specimens immersed in water at $70^{\circ} \mathrm{C}$.

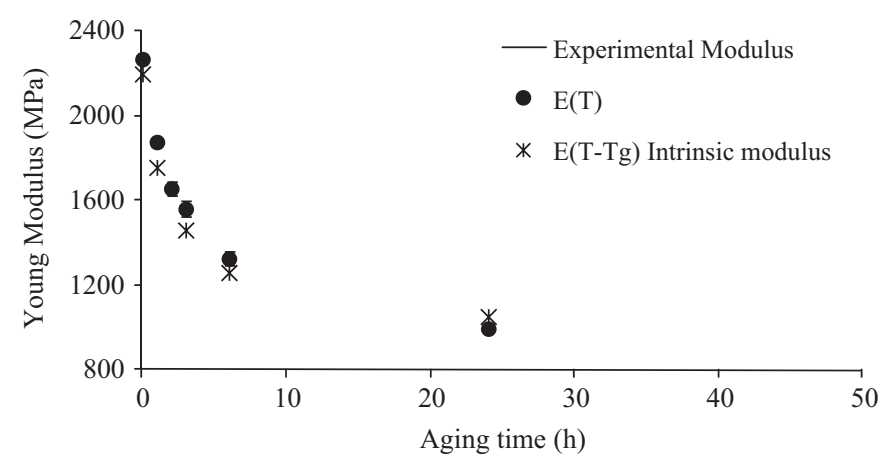

Fig. 11. Comparison between experimental (solid line) and simulated (circles and cross) evolution of Young's modulus (points at 5 and 15 days are not represented to improve the visualisation at short aging time).

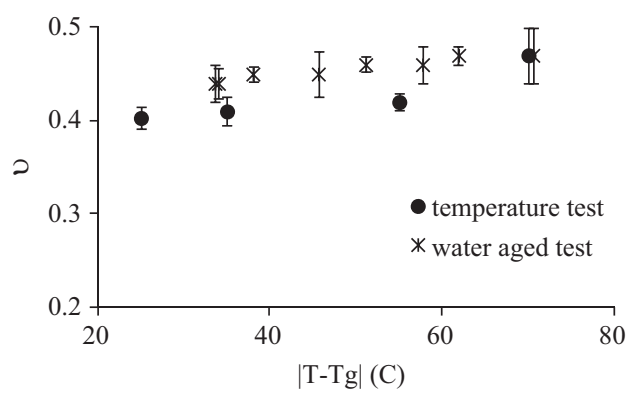

Fig. 12. Poisson's ratio as a function of $\left|T-T_{g}\right|$ for both types of experimental test in temperature and on aged specimens.

and gives a better estimation of the decrease of $E$ as a function of aging (black crosses in Fig. 11).

In Fig. 7, the comparison between the black (with triangles/ coupled effects) and the red (with circles/dry samples without coupled effects) curves reveals the intrinsic effects of water which finally is of second order confronted to the impact of $T_{\mathrm{g}}$ drift. For example (Fig. 7), the $T_{\mathrm{g}}$ drift is responsible for a decrease of $E$ of about $1400 \mathrm{MPa}$, while the intrinsic impact of water is only responsible for a decrease of $250 \mathrm{MPa}$.

As for $E$, Poisson's ratio is plotted as a function of $\left|T-T_{g}\right|$ in Fig. 12. The coupled effect of water and temperature on its value is quantified. There is an intrinsic impact of water but it has not been integrated in the model since it is of second order compared with the impact of the drift of $T_{\mathrm{g}}$. The black crosses curve is directly included in the model.

\subsection{Behaviour law-application}

A simple elasto-plastic law is proposed to estimate the behaviour of the adhesive during its aging in water at $70{ }^{\circ} \mathrm{C}$ and during the tensile test. In the classical elasto-plastic model, assuming that all deformations are small, it is possible to present the tensor of deformations as the sum:

$\varepsilon_{i j}=\varepsilon_{i j}^{\mathrm{EL}}+\varepsilon_{i j}^{\mathrm{PL}}+\varepsilon_{i j}^{\mathrm{RH}}+\varepsilon_{i j}^{\mathrm{T}}$

here $\varepsilon_{i j}^{\mathrm{EL}}$ is the elastic strain tensor and $\varepsilon_{i j}^{\mathrm{PL}}$ is the plastic strain tensor. Variations of the temperature and the humidity generate expansions which are considered to be isotropic. These expansions are represented by two tensors $\varepsilon_{i j}^{\mathrm{T}}$ and $\varepsilon_{i j}^{\mathrm{RH}}$ correspondingly.

The adhesive behaviour is supposed to be elasto-plastic and isotropic; in elastic region Hooke's law is accepted. The constitutive law can be written as follows:

$\left.\sigma_{i j}=\frac{E}{(1+v)(1-2 v)} \quad v \varepsilon_{i j}^{\mathrm{EL}}+\sum_{k}(1-2 v) \varepsilon_{k k}^{\mathrm{EL}} \delta_{i j}\right)$

where $\sigma_{i j}$ is the stress tensor, $v$ is Poisson's ratio, $E$ is Young's modulus, $\delta_{i j}$ Kroneker symbol, subscripts $i$ and $j$ evolve from 1 to 3. Young's modulus depends on the temperature and the humidity via function $\left|T-T_{g}\right|$, Fig. 7. Poisson's ratio also depends on the temperature and the humidity via function $\left|T-T_{\mathrm{g}}\right|$ show in Fig. 12. law:

Thermal strain is determined by the classical linear expansion

$\varepsilon_{i j}^{\mathrm{T}}=\alpha^{\mathrm{T}}\left(T-T_{0}\right) \delta_{i j}$

where $\alpha^{\mathrm{T}}$ is the linear thermal expansion coefficient, $T$ is the current temperature, $T_{0}$ is the reference temperature. The thermal expansion coefficients depend on temperature, the law is linear per piecewise as show in Fig. 13. It is obtain on a DMA by measuring the displacement of the top of a specimen cooled from rubbery state at a very slow rate $\left(0.5^{\circ} \mathrm{C} / \mathrm{min}\right)$. 


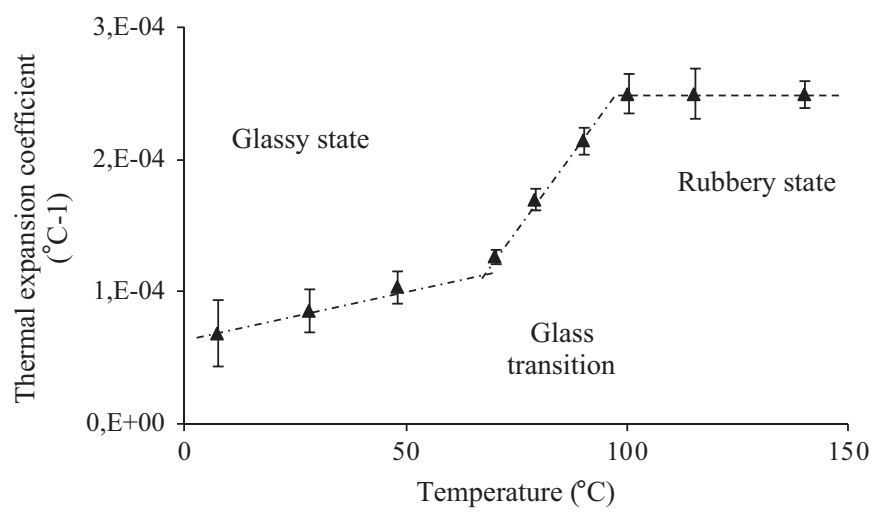

Fig. 13. Experimental thermal expansion coefficient as a function of temperature.

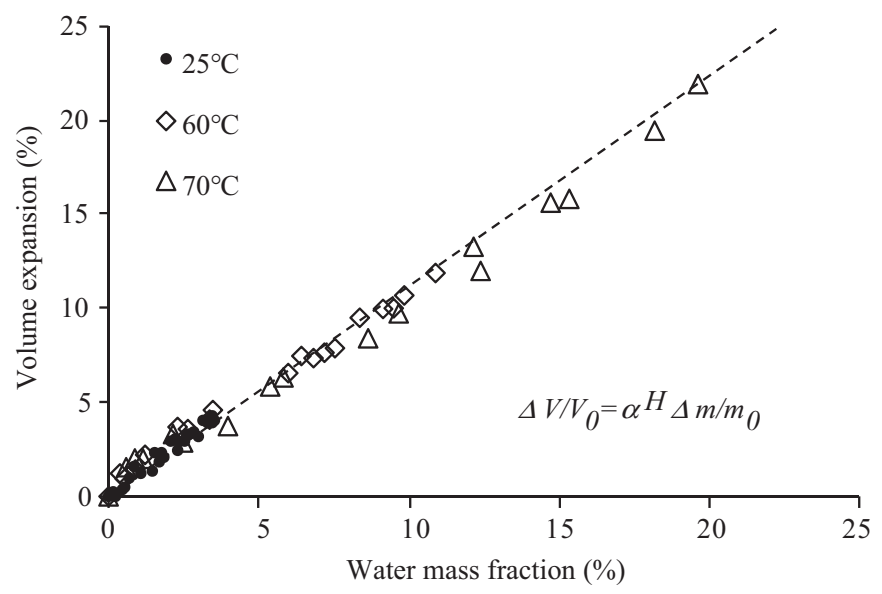

Fig. 14. Experimental volume expansion as a function of water mass fraction at different temperature-Swelling coefficient.

The swelling-expansion strain is determined by a linear law:

$\varepsilon_{i j}^{\mathrm{RH}}=\frac{\alpha^{\mathrm{H}}}{3} Y_{\mathrm{w}} \delta_{i j}$

where $Y_{\mathrm{w}}$ is the mass fraction of water and $\alpha^{\mathrm{H}}$ the linear swelling expansion coefficient which is determined in Fig. 14, representing the volume expansion as a function of water mass uptake. Volume was determined by recording the mass of coupons in air and in water at room temperature and by applying the relation (5) born from the law of Archimedes

$V=\frac{m_{\mathrm{a}}}{\left(\frac{m_{\mathrm{a}} d_{\mathrm{w}}}{A\left(m_{\mathrm{a}}-m_{\mathrm{w}}\right)}\right)+d_{\mathrm{a}}}$

where $m_{\mathrm{a}}$ and $m_{\mathrm{w}}$ are the masses of an adhesive sample, respectively, in air and in water, $d_{\mathrm{a}}$ and $d_{\mathrm{w}}$ are the density of air and water at room temperature and $A$ is a constant integer representing the effect of Archimede's force on the weighing device. The volume expansion as a function of mass uptake does not depend a lot on temperature and water concentration. It is considered as a constant:

$\alpha^{\mathrm{H}}=1.22$

The plasticity behaviour of adhesive is described by PrandtlReuss theory. The von Mises yield function is defined as follows:

$f\left(\sigma_{i j}\right)=\sqrt{\frac{3}{2} S_{i j} S_{i j}}-\sigma_{0}$

and the Von Mises yield criterion is presented as:

$f\left(\sigma_{i j}\right)=0$

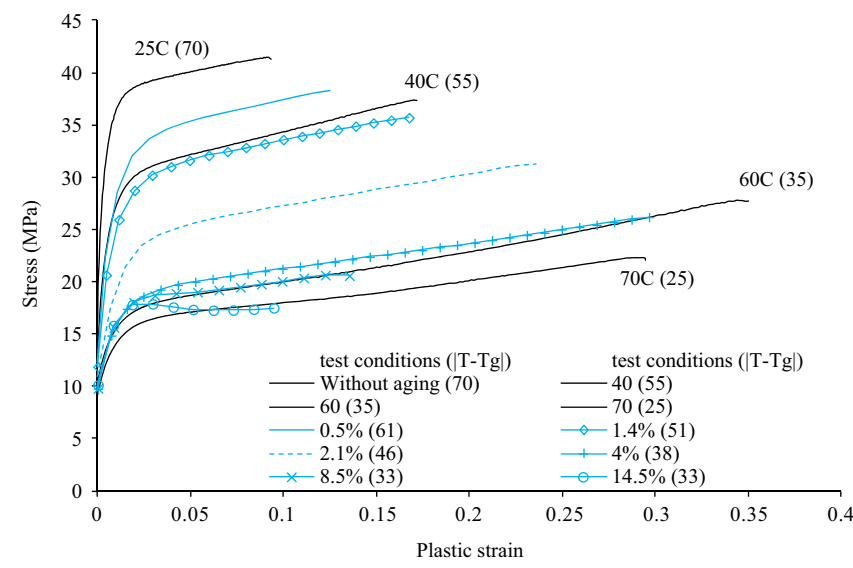

Fig. 15. Experimental hardening curves as a function of $\left|T-T_{\mathrm{g}}\right|$ for tests in temperature and tests on aged specimens. For each curve, the first value indicates the condition of test $\left(25^{\circ} \mathrm{C}\right.$ : test at $25^{\circ} \mathrm{C}, 2.1 \%$ : test on a sample containing $2.1 \%$ of water in mass), the second value is the $\left|T-T_{g}\right|$ parameter for the test.

where $\sigma_{i j}$ is the stress tensor. The term $\sigma_{0}=\sigma_{0}(T, R H)$ is the yield strength depending on the temperature and the relative humidity (see Fig. 8); $S_{i j}=\sigma_{i j}-\frac{1}{3} \sigma_{k k} \delta_{i j}$ is the deviator stress tensor. When the inequality $f\left(\sigma_{i j}\right)<0$ is verified, the material has elastic behaviour.

The plasticity evolutions are described by isotropic hardening curves of adhesive. As for Young's modulus, theses curves depend on temperature and water concentration through the parameter $\left|T-T_{\mathrm{g}}\right|$. The intrinsic impact of water is of second order Fig. 15 since for a same value of $\left|T-T_{\mathrm{g}}\right|$ and whatever the type of test hardening curves are very close. For finite element simulation experimental curves Fig. 15 have been employed.

According to the Prandtl-Reuss theory, the plastic increment tensor is proportional to the derivative of the yield function (7):

$d \varepsilon_{i j}=-\frac{\partial f}{\partial \sigma_{i j}} d \lambda$

where $d \lambda$ is the plastic multiplier calculated by the consistent relation $(d f=0)$ during the hardening. The plastic multiplier corresponds to the increment of the equivalent plastic strain.

In order to apply the elasto-plastic behaviour law, tensile tests on aged specimens are simulated taking into account gradients of water concentration in the section. Results are given in Fig. 16. It can be observed that initial behaviour is well described whatever the aging period. Before aging and after saturation is reached, the non-linear behaviour is also well predicted. Deviations appear at intermediate aging time probably because of a wrong description of the water concentration gradients. For such aging period, gradients are very important and only a minor deviation in the prediction of concentration can be responsible of important differences in mechanical properties. Another explanation could be the lack of description concerning damage and hydrostatic stress dependency of hardening which is highlighted in Fig. 17. But, such underestimation of the volumic strain caused by the mechanical test is of second order in front of the impact of water on swelling. The integration of a Drucker-Präger criterion would probably help taking into account this non-linear effect but has not been evaluated in this work. It also appears that fracture strains are not reached correctly. Actually in Abaqus ${ }^{\mathbb{R}}$, with such elasto-plastic model, it is not possible to simulate a softening of the material and the section reduction of the sample before fracture. As a consequence, this model is not able to precisely predict fracture. However, it gives an indication about the maximal stress reached in the section at the beginning of softening. 


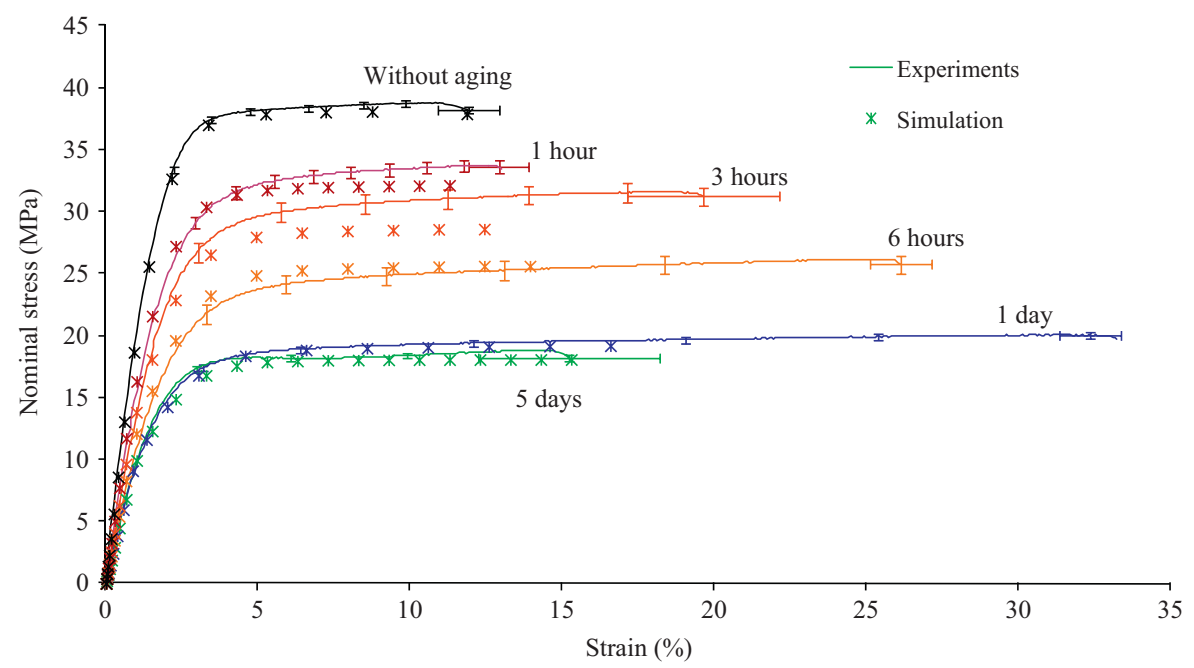

Fig. 16. Experimental and simulated behaviour of aged specimen after loading in tension.

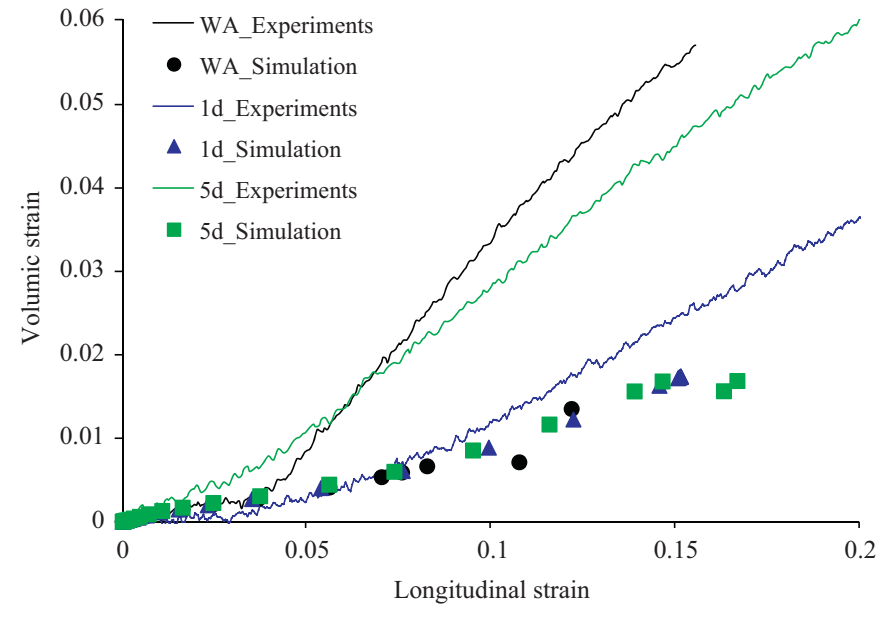

Fig. 17. Experimental and simulated impact of aging on the evolution of volume strain as a function of longitudinal strain - Impact of hydrostatic stress on the behaviour of bulk adhesive (WA: without aging, $1 \mathrm{~d}$ : aging of 1 day, $5 \mathrm{~d}$ : aging of $5 \mathrm{~d}$ ).

\subsection{Discussion}

The first step of this work, which consisted in the development of a behaviour law for the bulk adhesive during aging in water at $70{ }^{\circ} \mathrm{C}$, gives good prediction of the response to tensile test in increasing load at a specified crosshead speed. Little deviations are observed for the non-linear behaviour. Obviously, this model is not sufficient. It does not include visco-elastic effects during load and unload. Here, unload is describing by a linear law. However, it still integrates an important number of coupled effects and should allow evaluating precisely the order of size of stresses in the adhesive joint. Concerning the tensile test, it generates deformation rate in the single lap joint close to the rate applied to the crosshead and are carried out in increasing load. As a reminder, the objective is not to predict the joint behaviour in every possible situation but to obtain information on stress level reached during the normalised test in the automotive field. The behaviour law is reliable in this specific situation.

At this point one can ask if this model describing the bulk behaviour in terms of mechanics and physics of diffusion is able to reproduce the behaviour of the adhesive in the joint. Such question relates to the notion of interphase. Near the substrate, adhesive polymerisation is known to be disturbed and the subsequent mechanical properties to be impacted. Roche et al. studied joints of aluminium and titanium bonded with epoxies and found an important decrease of $T_{\mathrm{g}}$ near the substrates which obviously results in a decrease of mechanical properties [32], while other authors reported no evidence of change in modulus near the substrate [33]. Diffusion of water in joints is sometimes found to be accelerated compared to bulk [31,34]. Such experimental measurement requires specific devices that were not in possession of the authors. In a first approach, the authors chose to consider the adhesive layer as bulk and the diffusion of water unmodified by the formation of interphase. Such hypothesis is strong and will probably leads to a shift in time concerning the diffusion, but it is necessary in order to approach the state of stress of the adhesive in the bonded joint after aging which is the first concern of this paper.

\section{Finite element study of humid aging of bonded joints}

In structural assemblies, adhesive layers are very thin and substrate's stiffness important. As a consequence, the stress field generated by differential swelling during the ingress of water can be very important and could explain in part the weakening of bonded joints. In such sandwich structure, it is difficult to predict which part is most impacted by aging and is responsible for failure. Here, it can be the interface which is chemically and/or mechanically degraded by water or it can be the adhesive which is plasticized. But, to determine the exact scenario of failure, knowing the state of stress in the adhesive layer is necessary. As a reason, it is of first importance to determine this stress field at which will be added mechanical stresses.

\subsection{Finite element model}

This simulation will not take the interface or interphase into account from a mechanical and physical point of view. This means that the adhesive and substrate cannot be separated during loading, the aging of interface and its degradation are not taken into account and the diffusion of water in the interphase is not modelled. It is of course possible to model all these aspects if one is able to evaluate experimentally the evolution of the mechanical behaviour of the interface and the diffusion process in this very thin layer.

A finite element model representing half of a bonded joint with conditions of symmetry is developed. Substrates are 


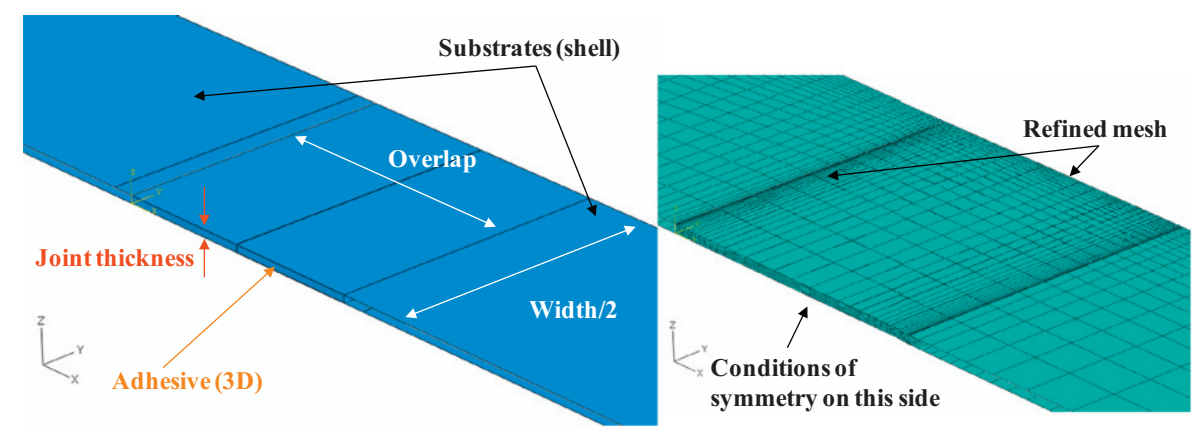

Fig. 18. FEM used to study the state of stress after aging in water and mechanical loading of a bonded joint.

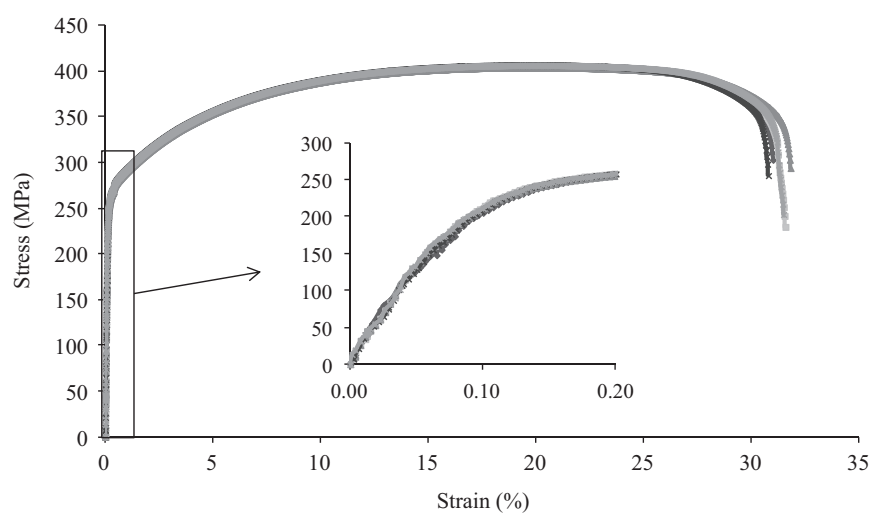

Fig. 19. Substrate's experimental behaviour.

modelled with shell elements (S8R5 in Abaqus $^{\circledR}$ ) and adhesive layer with 3D quadratic elements (C3D20 in Abaqus ${ }^{\circledR}$ ) (Fig. 18). In this first approach, adhesive and substrates are tied ('Tie' option in Abaqus ${ }^{\mathbb{R}}$ ) and cannot be separated. This means that interfacial fracture will not be modelled. Mesh is refined at extremities of overlap and edges where gradients of water concentration, properties and stress will be important (Fig. 18). There are 6 elements in the thickness of adhesive layer.

Concerning the diffusion of water, it is considered that there is no acceleration along interfaces. As a consequence, diffusion front is always parallel to edges. Substrate's behaviour has been characterised in tension (Fig. 19). A simple elasto-plastic law has been used to predict its behaviour in the tensile test of bonded joint.

\subsection{Impact of water sorption on stress field}

Diffusion of water at $70{ }^{\circ} \mathrm{C}$ is simulated in the FEM of bonded joint, it takes into account the swelling generated by temperature and humid aging. Fig. 20 displays the water location in the layer. After 14 days, the centre of the joint is not impacted by water. It would take approximately 30 days for a water molecule to reach the centre by considering the diffusion in the layer to be equivalent to the diffusion in the bulk. Calvez et al. found for the same adhesive joint that it took approximately 10 days to the water to reach the centre [28]. The diffusion of water is approximately accelerated 3 times in the joint. Fig. 20 also displays the resulting stress field obtained in half of the adhesive layer at the interface after 1, 5 and 14 days of aging where stresses are more critical. For short immersion times, a little volume of adhesive at extremities is affected by water and swell. But rigid adherents stop this displacement generating important strain gradients and subsequent compressive and shearing stresses at extremities of overlap, while tensile stresses appear inside the joint. Tear $\left(\sigma_{\mathrm{zz}}\right)$ and shear stress $\left(\sigma_{\mathrm{xz}}\right)$ are represented in Fig. 20. In-plane stresses $\left(\sigma_{\mathrm{xx}}\right.$ and $\left.\sigma_{\mathrm{yy}}\right)$ are not represented but have the same shape as $\sigma_{\mathrm{zz}}$ but with lower values (28 MPa at corners). $\sigma_{\mathrm{yz}}$ is not represented but have the same shape and values as $\sigma_{\mathrm{xz}}$, except it only concerns the upper side of the joint. As immersion time increases, gradients of water concentration decrease as well as tear stresses. Shear stresses remain important because of the presence of steel substrates. It is interesting to remark that tear stresses can take positive or negative values depending on the location, meaning that the adhesive can be either separated from the substrate (positive value) or compressed on the substrate (negative value). Stresses appearing during the ingression of water are surprisingly important. At extremities, important compressive stresses act on the aged part of the adhesive layer which mechanical properties are degraded. But, such stress field is not critical compared to the tensile stress field in the part of adhesive with no water (at corners, $\sigma_{\mathrm{zz}}$ reaches $32 \mathrm{MPa}$ ) which is close to the yield stress of the healthy adhesive (about $35 \mathrm{MPa}$ ). But, it is reasonable to think that at shorter immersion times (few hours for example) where gradients of water concentration and subsequent strain gradients are more important, the yield stress have been exceeded and the adhesive or interface damaged.

Concerning the adhesive, if during the aging period, the stress field exceeds the yield or fracture stress somewhere in the adhesive layer, the mechanical response of the bonded joint will be modified. To model such behaviour, a damageable elastoplastic law should be used. In this first study, the authors choose to only model the degradation of properties due to plasticisation. Concerning the interface, no information is in possession of the authors concerning the mechanical resistance of the interface in tension or shear, but it is reasonable to think that such stresses could damage the interface or generate small cracks and facilitate the interfacial fracture as observed experimentally after lapshear test.

At this point, one could also ask about the impact of compressive stresses on the sorption of water. Actually, such stress field could limit the growth of cavities occurring during water ingress and reduce the diffusion process and subsequent formation of gradients. This part of study is still in progress.

\subsection{Simulation of tensile test after aging of bonded joints}

Diffusion of water generates an important initial stress field in the adhesive layer and interface. In this part of the paper, tensile loading is simulated on aged bonded joints generating additional stresses. Stress and strain fields are observed at the interface and compared with experimental features.

To simulate tensile test, one end of a substrate is fixed while the displacement is imposed on the end of the other substrate. This displacement consists in an alignment of substrates corresponding 

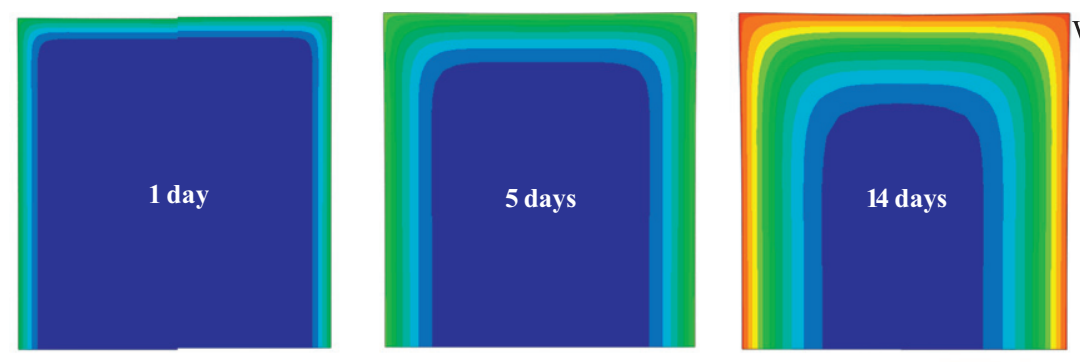

Water mass fraction $(\%)$
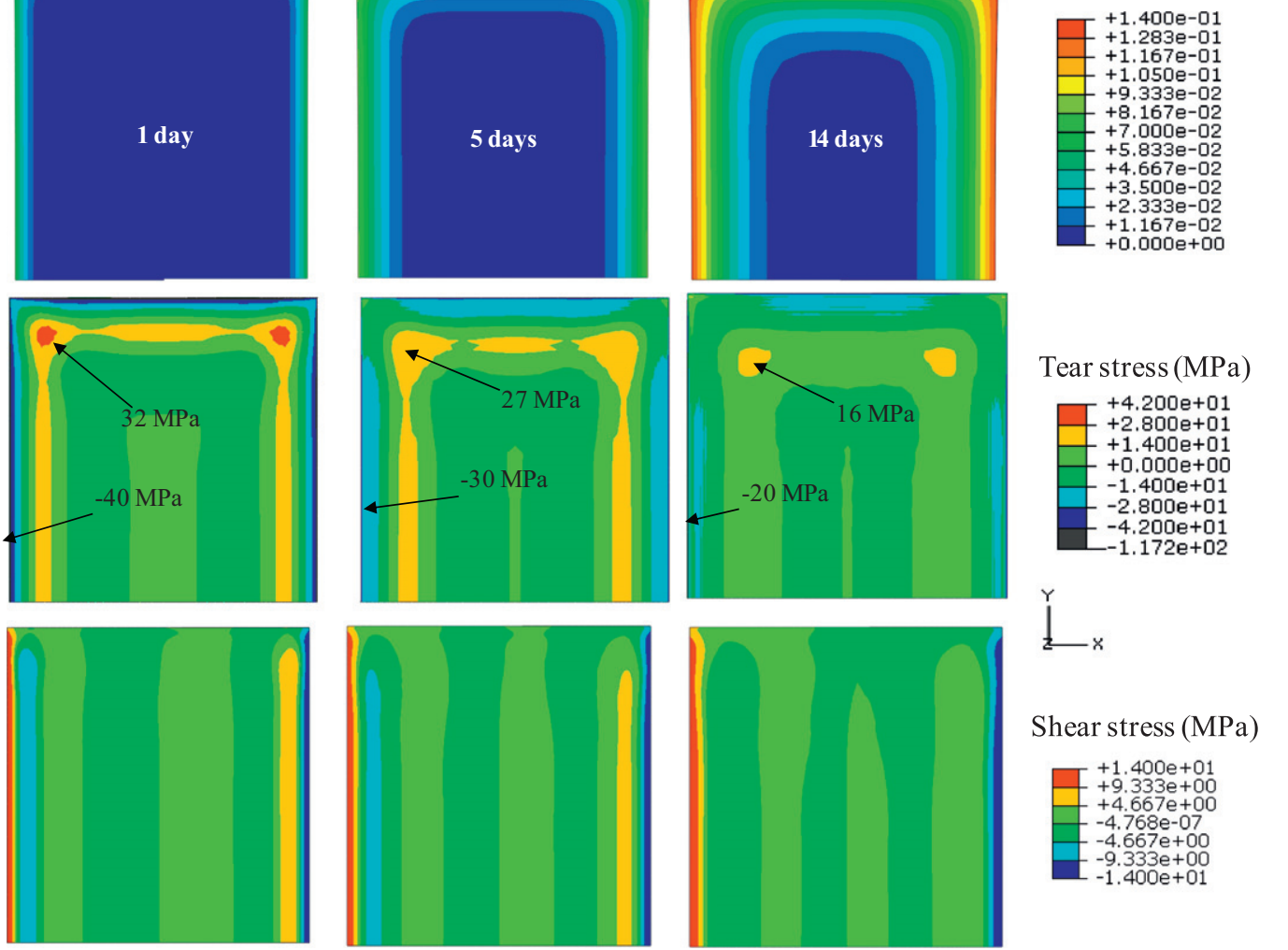

Tear stress $(\mathrm{MPa})$

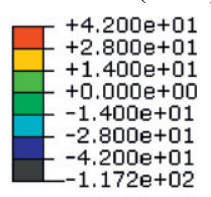

$\mathfrak{L}_{\mathrm{L}} \mathrm{x}$

Shear stress $(\mathrm{MPa})$

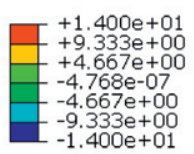

Fig. 20. Simulated water concentration and stress field (tear stress $\sigma_{\mathrm{zz}}$, shear stress $\sigma_{\mathrm{xz}}$ ) at interface between adhesive and substrates after 1,5 and 14 days of immersion in water at $70{ }^{\circ} \mathrm{C}$ (half of the joint is represented).
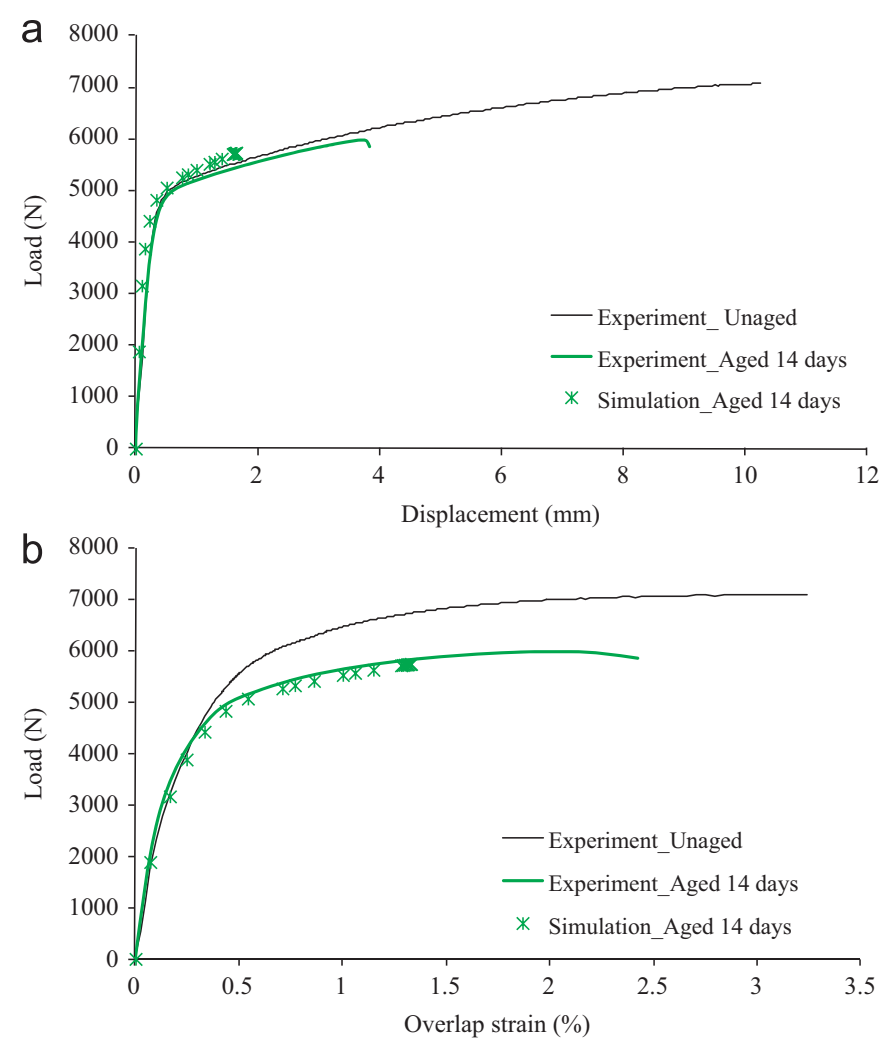

Fig. 21. Simulation of the behaviour of a 14 days aged bonded joint submitted to tensile test (a—global behaviour, b—overlap behaviour). to clamping step and the imposed elongation by crosshead. Results of the simulated tensile test on a bonded joint aged during 14 days at $70{ }^{\circ} \mathrm{C}$ are presented in Fig. 21. Prediction of both global behaviour, overlap and substrate deformation is satisfactory. The entire test could not have been simulated because of numerical problems encountered for this model which is not well adapted to large strains. Nevertheless, the prediction of deformation of the overlap is reasonably good and stress can be evaluated at the interface where it is supposed to be more important. Note that at interface, stress field is not symmetric and highest stress appears at the extremity of overlap where the substrate is loaded. As crack propagation has not been modelled, stress field is only analysed at experimental crack initiation load ( $\approx 4400 \mathrm{~N}$ ) in Fig. 22. Equivalent plastic strain (PEEQ) is observed as close as possible to experimental failure load $(\approx 5700 \mathrm{~N})$ in Fig. 23.

At extremities of overlap, there is a singularity which is responsible of a non-realistic prediction of stresses of more than $100 \mathrm{MPa}$. This singularity is due to an idealistic representation of the geometry (as shown in Fig. 3 the real geometry is complex and different for each specimen) and a step in the material heterogeneity (in the specimen, the interphase presents a short gradient of mechanical properties). The size of this singularity is approximately $50 \mu \mathrm{m}$. In such context, the stress level at extremities of overlap cannot be determined precisely. However, it is considered that maximal tear stress is close to the level outside the singularity which is about $23 \mathrm{MPa}$ in this simulation (Fig. 22). At extremities of overlap, the adhesive matrix is saturated in water and the ultimate tear stress for this level of concentration is close to $\sigma_{\mathrm{sat}}^{\text {ult }}=25 \mathrm{MPa}$. Shear stresses are important in the centre of the joint at the interface (20 MPa) and reduced at extremities of overlap ( $8 \mathrm{MPa}$ ). In the centre of overlap, adhesive is not degraded 

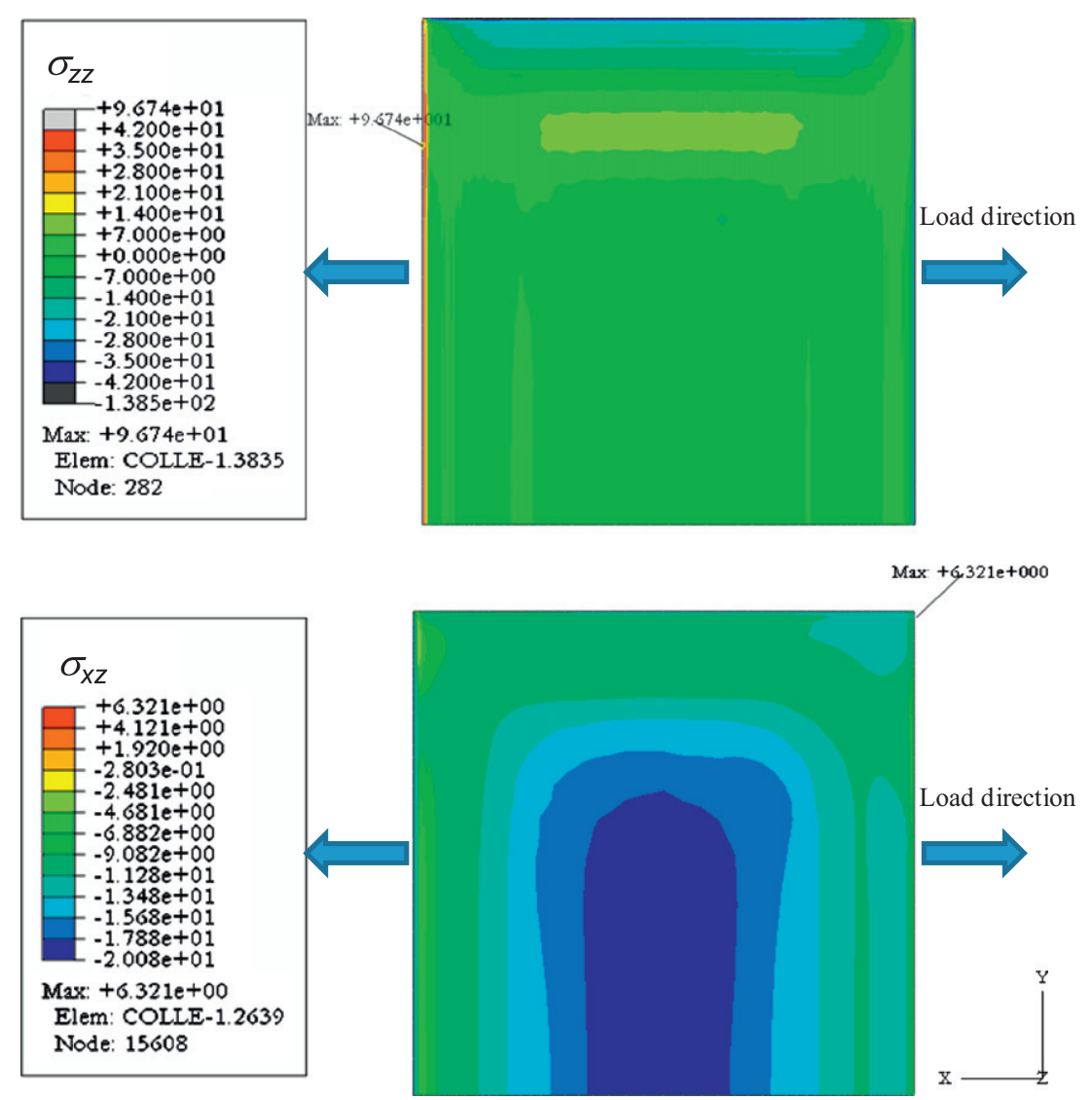

Fig. 22. Tear and shear stress at the interface for a $4400 \mathrm{~N}$ tensile test and after 14 days of aging in water at $70{ }^{\circ} \mathrm{C}$.
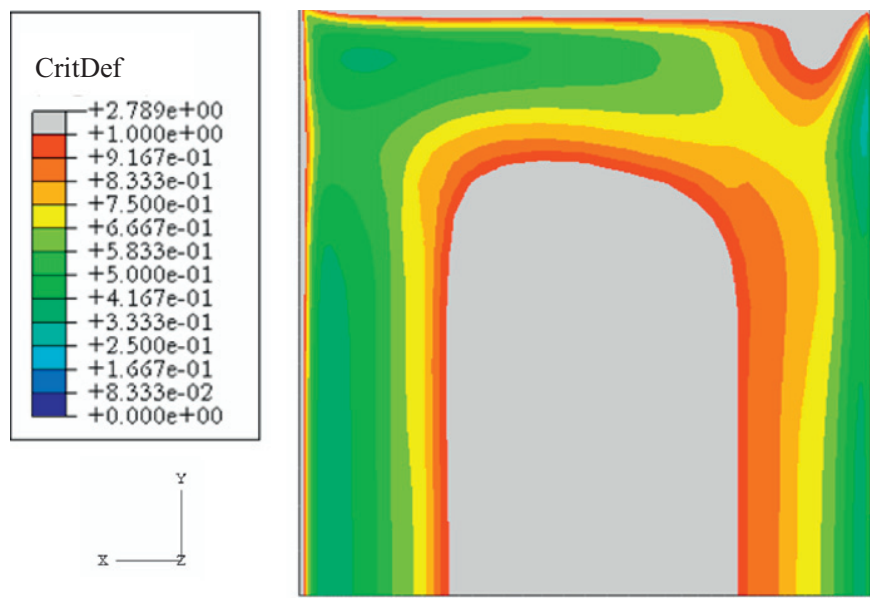

Fig. 23. PEEQ criterion at interface of a 14 days aged bonded joint for a load of $5700 \mathrm{~N}$.

and according to Von Mises, the ultimate shear stress without aging is $\tau^{\text {ult }}=\sigma^{\text {ult }} / \sqrt{3}=24 \mathrm{MPa}$, while when saturated it is of $14 \mathrm{MPa}$. As a consequence, fracture is more likely to initiate in the adhesive at extremities of overlap because of tear stress, as observed experimentally, but also in the centre of overlap because of shear stresses, even if this last state of stress is less critical. But since no information concerning the mechanical strength of the interface is in possession of the authors, it is not possible to conclude on the exact location of crack initiation. Interface can be less resistant than adhesive and break first. It just can be said that extremities of overlap and interfaces in particular are critical location.

A simple criterion is employed to study the PEEQ field (Fig. 23) taking into account the impact of water concentration gradients:

Criterion $=\frac{\text { PEEQ }^{\text {sim }}}{\text { PEEQ }^{\mathrm{e}}}$

$\mathrm{PEEQ}^{\text {sim }}$ represents the equivalent plastic strain simulated with Abaqus $^{\mathbb{R}}$ and PEEQ $^{\text {exp }}$ the experimental plastic strain at failure for the bulk adhesive. If this criterion is equal or superior to 1 , then the adhesive is considered to be broken. This criterion is evaluated at the interface of an aged joint loaded in tension at $5700 \mathrm{~N}$ (Fig. 23). The criterion is true at the extremities of overlap and in the centre of the joint which do not correspond to experimental observations.

Another approach to explain such results is proposed. Let us suppose that interface is not the weakest location after aging. Last simulation with perfect interfaces shows that, crack initiation should occur in the adhesive very close to the interface at extremities of overlap. It also shows that fracture should principally be caused by shear stresses and that its location should be near interface in the middle of overlap and not at extremities of overlap. This scenario is in contradiction with experimental observations meaning that interface is most probably the weakest element in the joint after aging in water. In fact, crack initiates at the interface at extremities of overlap. It propagates along the interface, reducing the overlap length. When overlap length decreases, tear stresses increase and this is in favour of propagation along the interface. Shear stresses are responsible of the final failure which occurs in the adhesive layer. 


\section{Conclusion}

An experimental work on bulk adhesive aged in water has been carried out and a coupled elasto-plastic law has been proposed to model simultaneously its intrinsic behaviour as a function of temperature and water concentration. It allows predicting the tensile tests on aged adhesive specimens and the volume change due to temperature and diffusion of water. This paper also covers experimental work on bonded joints aged in water at $70{ }^{\circ} \mathrm{C}$ and submitted to tensile tests. It reveals that initial behaviour (initial stiffness) of joints is not impacted by water while the fracture mode evolves from a mainly cohesive $(80 \%)$ to an adhesive fracture. A finite element model of the bonded joint has been developed to model the diffusion of water in the adhesive layer and the tensile tests. Results show that:

1) Stresses generating by ingression of water are not negligible.

2) For a load that experimentally leads to crack initiation and final fracture, the state of stress in the adhesive layer is not that critical. This simulation tends to confirm that interface is the most favourable location of crack propagation and weakest part of the joint after aging. That would tend to confirm that interface has been highly impacted and damaged by water.

The adhesive layer is highly plasticized by water, it can be easily overloaded transferring many stresses towards the interface which is also degraded by water and break. We have demonstrated that the adhesive behaviour is of second order in this aging process of the bonded joint. The numerical tool is able to predict the behaviour of the joint before the crack appears at the interface. A comparison between experimentation and simulation will provide all information required to characterise the aging of the interface. At this stage, it seems essential to model the crack propagation with CZM approach or continuum damage model. Some authors propose this approach and obtain good prediction $[21,25,26]$. Such approach requires the mechanical properties of the interface (stiffness, ultimate strength ...) as a function of temperature and water concentration to describe its behaviour in the finite element model. It would also require the water diffusion kinetics along the interface. Such experimental work is heavy and to avoid it, one could develop a finite element model with cohesive zone for example, and include different traction-separation laws as a function of water until a good prediction is obtained. Another improvement should be to include the impact of hydrostatic stress and damage in the behaviour law of the bulk adhesive, since, it is known that at corners, very important triaxial stresses are present. Finally, as mentioned before, the impact of stress on diffusion should also be included in order to improve the description of gradients in the adhesive layer.

\section{References}

[1] Hoang-Ngoc CT, Paroissien E. Int J Adhes Adhes 2010;30:117.

[2] Osnes H, McGeorge D. Compos Part B Eng 2005;36:544.

[3] Earl JS, Dulieu-Barton JM, Shenoi RA. Compos Sci Technol 2003;63:211

[4] Fox TG. Bull Am Phys Soc 1956;1:123.

[5] Tcharkhtchi A, Bronnec PY, Verdu J. Polymer 2000;41:5777.

[6] Zhou JM, Lucas JP. Polymer 1999;40:5513.

[7] Roy A, Gontcharova-Bénard E, Gacougnolle J-L, et al. In: Schapery RA, Sun CT, editors. American Society for Testing and Materials, Time Dependent and Non-Linear Effects in Polymers and Composites, ASTM STP 1357; 2000 p. 353.

[8] Popineau S, Shanahan MER. Int J Adhes Adhes 2006;26:363.

[9] Weitsman Y. J Compos Mater 1977:11:378.

[10] Verdu, J. Techniques de l'Ingénieur, 2000, Vol. AM3165.

[11] Xiao GZ, Delamar M, Shanahan MER. J Appl Polym Sci 1997;65:449.

[12] Brewis DM, Comyn J, Shalash RJA, et al. Polymer 1980;21:357.

[13] Ivanova KI, Pethrick RA, Affrossman S. J Appl Polym Sci 2001;82:3477.

[14] Leger R, Roy A, Grandidier JC. Int J Adhes Adhes 2010;30:744.

[15] Mubashar A, Ashcroft IA, Critchlow GW, et al. Int J Adhes Adhes 2009;29:751.

[16] Zannideffarges MP, Shanahan MER. Int J Adhes Adhes 1993;13:41.

[17] De'Neve B, Delamar M, Nguyen TT, et al. Appl Surf Sci 1998;134:202.

[18] Bordes M, Davies P, Cognard JY, et al. Int J Adhes Adhes 2009;29:595.

[19] Bresson G, Jumel J, Shanahan MER, et al. Int J Adhes Adhes 2012;35:27.

[20] Sargent JP. Int J Adhes Adhes 2005;25:247.

[21] Blackman BRK, Hadavinia H, Kinloch AJ, et al. Int J Fract 2003;119:25.

[22] Kinloch AJ, Little MSG, Watts JF. Acta Mater 2000:48:4543.

[23] Wahab MMA, Crocombe AD, Beevers A, et al. Int J Adhes Adhes 2002;22:61.

[24] Crocombe AD, Hua YX, Loh WK, et al. Int J Adhes Adhes 2006;26:325.

[25] Liljedahl CDM, Crocombe AD, Wahab MA, et al. Int J Adhes Adhes 2007; $27: 505$

[26] Hua Y, Crocombe AD, Wahab MA, et al. Int J Adhes Adhes 2008;28:302.

[27] Crocombe AD. Int J Adhes Adhes 1997;17:379.

[28] Calvez P, Bistac S, Brogly M, et al. J Adhes 2012;88:145.

[29] Marder AR. Prog Mater Sci 2000;45:81.

[30] Bowditch MR. Int J Adhes Adhes 1996;16:73.

[31] Zannideffarges MP, Shanahan MER. Int J Adhes Adhes 1995;15:137.

[32] Roche AA, Bouchet J, Bentadjine S. Int J Adhes Adhes 2002;22:431.

[33] Davies P, Sohier L, Cognard JY, et al. Int J Adhes Adhes 2009;29:724.

[34] Wapner K, Stratmann M, Grundmeier G. Electrochim Acta 2006;51:3303. 